\title{
Development of long term use of psychotropic drugs by general practice patients
}

\author{
ANDREA MANT， PAUL DUNCAN-JONES， DEBORAH SALTMAN， CHARLES BRIDGES-WEBB, \\ LINDA KEHOE, GWENDA LANSBURY, ALAN H B CHANCELLOR
}

\begin{abstract}
From 1984 to 1986 a prospective study was conducted of 104 general practice patients who started treatment with a benzodiazepine or an antidepressant drug. The duration of reported use of the drugs was two months for $45 \%$ of patients, four months for $17 \%$ of patients, and six months for $15 \%$. Type of drug, age, and level of education were found to be predictive of continuing use.
\end{abstract}

General practitioners have a significant effect on their patients'

\footnotetext{
General Practice and Primary Care Research Unit, Royal Australian College of General Practitioners, Sydney, Australia $\mathbf{2 0 0 0}$

ANDREA MANT, MA, FRACGP, director

LINDA KEHOE, BSC, research assistant

GWENDA LANSBURY, BA, BAPPLSCI, research assistant

ALAN H B CHANCELLOR, FRACP, FRACGP, general practitioner
}

National Health and Medical Research Council, Social Psychiatry Research Unit, Australian National University

PAUL DUNCAN-JONES, MA, senior research scientist. Mr Duncan-Jones died in 1987.

School of Community Medicine, University of New South Wales DEBORAH SALTMAN, MB, BS, lecturer

Department of Community Medicine, University of Sydney CHARLES BRIDGES-WEBB, MD, FRACGP, head of department

Correspondence to: Dr Mant. use of drugs and, with careful selection and review when prescribing, may help to prevent dependence on psychotropic drugs.

\section{Introduction}

Patients with psychological disturbances commonly present to general practitioners. In a previous survey of Australian general practices in 1976, 17\% of consecutive adult attenders had significant psychological illness. ${ }^{1}$ Twenty eight per cent of these patients were given prescriptions for a psychotropic drug. Around $10 \%$ of the adult population report recent use of a psychotropic drug in household surveys, and roughly $20 \%$ of users or $2 \%$ of the general population report use for periods exceeding four months. ${ }^{23}$

Around $20 \%$ of general practice patients receive a prescription for a psychotropic drug. ${ }^{47}$ Fifteen per cent of psychotropic drug recipients received supplies sufficient for more than a year in a three year study. ${ }^{4}$ An earlier practice survey had estimated that $4.5 \%$ of the population at risk ( $25 \%$ of users) received at least one prescription every four months.

Benzodiazepines and antidepressants are the two most commonly prescribed groups of psychotropic drugs in general practice. ${ }^{4}$ Clinicians are advised to prescribe benzodiazepines for short periods as long term use is associated with dependence and a withdrawal syndrome. ${ }^{8-11}$ Some patients, however, with chronic anxiety disorders or chronic insomnia require continuing treatment with benzodiazepines. ${ }^{12-14}$ Antidepressants usually need to be prescribed for three to six months for depressive disorders, with a reduced dosage maintained for six to 12 months after recovery. ${ }^{15}$ The importance of alternatives to pharmacological treatment, especially for minor affective disorders, has been emphasised. ${ }^{12} 1617$

The probability that short term use of psychotropic drugs will 
become long term use has not been established prospectively from direct interviews with patients. Indirect methods estimate that $20 \%$ of patients continue use at six months. ${ }^{18} 19$ We enrolled general practice patients in a prospective study and explored possible predictors of continuing use.

TABLE I-Patient characteristics

\begin{tabular}{|c|c|}
\hline Characteristic & No of patients \\
\hline $\operatorname{Sex}(M / F)$ & $26 / 78$ \\
\hline \multicolumn{2}{|l|}{ Age (years): } \\
\hline $18-34$ & 26 \\
\hline $35-54$ & 43 \\
\hline$>55$ & 35 \\
\hline \multicolumn{2}{|l|}{ Medication prescribed: } \\
\hline Benzodiazepines & 60 \\
\hline Antidepressants & 44 \\
\hline \multicolumn{2}{|l|}{ Marital state: } \\
\hline Married (or cohabiting) & 63 \\
\hline Single & 41 \\
\hline \multicolumn{2}{|l|}{ Level of education: } \\
\hline Did not complete secondary & 34 \\
\hline Completed secondary & 70 \\
\hline \multicolumn{2}{|l|}{ Employment state: } \\
\hline In paid work & 44 \\
\hline Not in paid work & 60 \\
\hline \multicolumn{2}{|l|}{ Daily alcohol consumption (g): } \\
\hline $0-40 \mathrm{~g}$ (women); $0-60 \mathrm{~g}($ men $)$ & 88 \\
\hline$>40 \mathrm{~g}($ women $) ;>60 \mathrm{~g}(\mathrm{men})$ & 16 \\
\hline \multicolumn{2}{|l|}{ Daily tobacco consumption (cigarettes): } \\
\hline $0-10$ & 69 \\
\hline$>10$ & 35 \\
\hline \multicolumn{2}{|c|}{ Total score on general health questionnaire: } \\
\hline$>4$ & 67 \\
\hline $0-3$ & 37 \\
\hline \multicolumn{2}{|l|}{ Doctor's assessment: } \\
\hline Mainly physical & 27 \\
\hline Mainly psychological & 75 \\
\hline Not known & 2 \\
\hline \multicolumn{2}{|l|}{ Perceived general health: } \\
\hline Good & 28 \\
\hline Fair & 24 \\
\hline Poor & 51 \\
\hline Not known & 1 \\
\hline \multicolumn{2}{|c|}{ Score on Eysenck personality inventory. Neuroticism scale: } \\
\hline$>4$ & 74 \\
\hline $0-3$ & 29 \\
\hline Not known & 1 \\
\hline
\end{tabular}

\section{INITIAL QUESTIONNAIRES}

New users were asked about health, current tobacco and alcohol consumption, educational attainment, employment state, marital state, age, and sex. They completed the 12 item version of the general health questionnaire. ${ }^{21}$ In the general practice setting scores of 4 or more on the general health questionnaire indicate a high probability of minor psychiatric illness, mainly anxiety and depression. Patients also completed a short form of the Eysenck personality inventory, from which we used an 8 item ("trait neuroticism") scale (N-scale). ${ }^{22}$ This measures a stable personality trait predisposing to higher or lower levels of intermittent or chronic psychological illness. Scores of 4 or more on the N-scale of the Eysenck personality inventory were taken to denote significant "trait neuroticism."

Study doctors indicated the name of the psychotropic drug, the dosages prescribed, whether advice was given about duration of use, and the extent to which they considered the patients to have psychiatric or physical problems. $^{23}$

\section{FOLLOW UP QUESTIONNAIRES}

Respondents were asked whether they were taking the benzodiazepine or antidepressant prescribed on entry to the study. The number of tablets used daily (on days of use) and the strength of the medication were noted. The pattern of drug use during each four week period was coded as follows: $1=$ four weeks every day; 2 =four weeks intermittently; 3 =two weeks or more, every day; $4=$ two weeks or more, intermittently; $5=$ less than two weeks, every day; $6=$ less than two weeks, intermittently; $7=$ no use.

\section{METHODS OF ANALYSIS}

Duration of use was investigated by means of survival analysis. ${ }^{18}$ Users were defined as those patients who were taking drugs daily or intermittently for four weeks or daily for two weeks or more-that is, response categories 1 to 3). Patients who stopped taking the drugs for more than one month were considered to have reached the termination point for the survival analysis. Predictors were constructed from patient characteristics as identified in the home interview (table I).

Significance of the distribution of continuing users for each subgroup of predictors was determined by calculating the statistic $\mathrm{D}$, equivalent to the $\chi^{2}$ statistic, according to the method of Lee and Desu. ${ }^{24}$ Confidence intervals

TABLE II-New users of benzodiazepines and antidepressants continuing use ${ }^{\star}$ after six months

\begin{tabular}{|c|c|c|c|c|c|c|}
\hline \multirow[b]{2}{*}{ Month } & \multicolumn{2}{|c|}{$\begin{array}{l}\text { Patients receiving benzodiazepines } \\
\qquad(\mathrm{n}=60)\end{array}$} & \multicolumn{2}{|c|}{$\begin{array}{l}\text { Patients receiving antidepressants } \\
\qquad(\mathrm{n}=44)\end{array}$} & \multicolumn{2}{|c|}{ All patients $(n=104)$} \\
\hline & No $(\%)$ & $\begin{array}{l}95 \% \text { Confidence } \\
\text { intervals } \nmid(\%)\end{array}$ & No $(\%)$ & $\begin{array}{l}95 \% \text { Confidence } \\
\text { intervals } \nmid(\%)\end{array}$ & No (\%) & $\begin{array}{l}95 \% \text { Confidence } \\
\text { intervals } \uparrow(\%)\end{array}$ \\
\hline 1 & $36(60)$ & 47 to 72 & $33(75)$ & 59 to 86 & $69(66)$ & 56 to 75 \\
\hline 2 & $23(38)$ & 26 to 52 & $24(55)$ & 39 to 69 & $47(45)$ & 36 to 55 \\
\hline 3 & $10(17)$ & 9 to 29 & $21(48)$ & 33 to 63 & $31(30)$ & 21 to 40 \\
\hline 4 & $8(13)$ & 6 to 25 & $14(32)$ & 19 to 48 & $22(21)$ & 14 to 30 \\
\hline 5 & $7(12)$ & 5 to 23 & $11(25)$ & 14 to 41 & $18(17)$ & 11 to 26 \\
\hline 6 & $6(10)$ & 4 to 21 & $10(23)$ & 12 to 38 & $16(15)$ & 9 to 24 \\
\hline
\end{tabular}

${ }^{\star}$ Continuing user=patient taking drugs daily or intermittently for four weeks, or daily for two weeks or more, in each month. Patients who stopped use for more than one month were considered to have reached termination point. $+95 \%$ Confidence intervals calculated according to the method described by Armitage and Berry. ${ }^{25}$

\section{Methods}

\section{STUDY POPULATION}

The cohort of 104 patients is described elsewhere. ${ }^{20}$ Patients were eligible for the study if they were given a prescription for a benzodiazepine or antidepressant, provided they had not used the same or similar medication in the preceding three months. Proportional sampling was used to select 291 general practitioners from 21 of the 44 local government areas in Sydney, Australia. Two hundred and twenty doctors agreed to contribute patients. Only 62 general practitioners, however, could contribute at least one patient to the study within the four week recruiting period. Recruitment was designed in three phases, between 1984 and 1986, so that entry and follow up took place in all seasons. New users were interviewed at home with a structured questionnaire. Subsequent interviews took place at four weekly intervals by telephone. were calculated according to the method described by Armitage and Berry. ${ }^{25}$

Compliance with the doctor's recommended regimen, based on patients' reported usage, and daily dosages were analysed for all patients.

\section{Results}

Sixteen patients (15\%) were still taking psychotropic drugs at six months. The median duration of use for all new users was 1.8 months. The pattern of continuing use in each month is shown in table II.

Some patients who stopped taking the drugs for more than one month subsequently resumed use. For months two to six the number of patients resuming use (in response categories $1-3$ ) was $3,5,5,9$, and 12 , respectively. Three patients did not complete six follow ups; all had reached the termination point for the survival analysis. 


\section{TYPE OF MEDICATION}

Antidepressants used by patients in the study were: doxepin, trimipramine, imipramine, desipramine, amitriptyline, nortriptyline, and mianserin. Benzodiazepines used were diazepam, oxazepam, temazepam, nitrazepam, bromazepam, and chlordiazepoxide.

Users of antidepressants were more likely to continue drug treatment than users of benzodiazepines $(D=5 \cdot 78 ; d f=1 ; p=0 \cdot 016)$. The median duration of use for new users of benzodiazepines was 1.5 months and that for those taking antidepressants was 2.7 months. Figure 1 shows the proportions continuing in each month shown. There were no significant differences in the median durations of use for diazepam, oxazepam, temazepam, or other generic benzodiazepines.

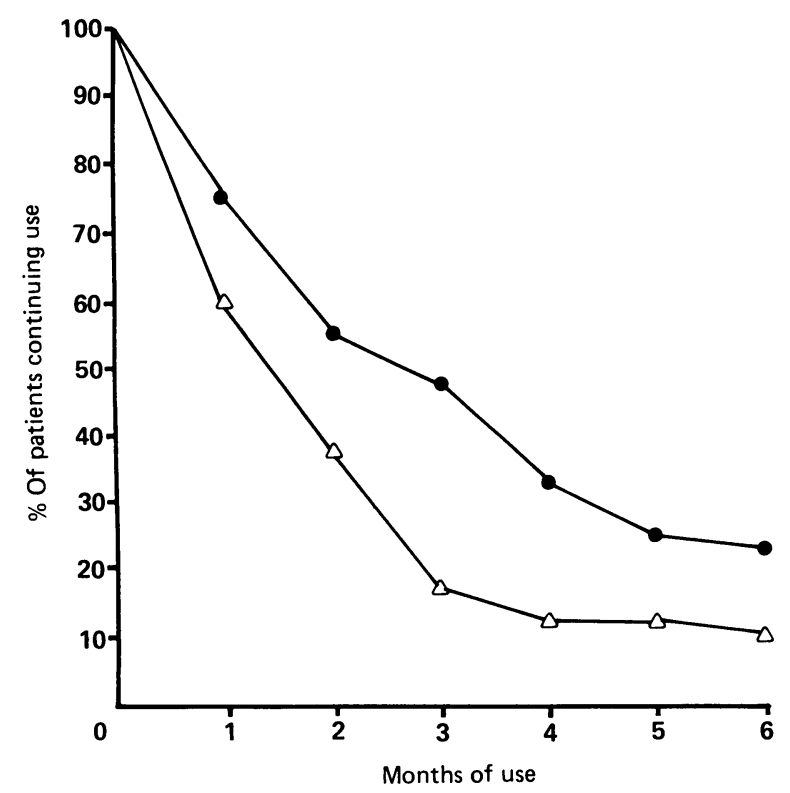

Ho 1 -Percentage of new users of benzodiazepines $(\triangle)(n=60)$ and antidepressants $(n)(n=44)$ continuing use over six months.

\section{PATIENT CHARACTERISTICS}

New users aged 55 years or over were more likely to continue use than younger patients $(\mathrm{D}=14 \cdot 88 ; \mathrm{df}=2 ; \mathrm{p}=0.001)$. The median durations of use were 3.3 months ( 55 years and over), 1.5 months ( 35 to 54 years), and 1.1 months (18 to 34 years). Figure 2 shows the proportions of patients continuing use in each month.

Age was a significant factor in predicting continuing use for both benzodiazepines $(D=6.81 ; d f=2 ; p=0.033)$ and for antidepressants $(D=$ $9 \cdot 60 ; d f=2 ; p=0.008)$. A lower level of education was also a significant predictor of continuing use for patients aged 55 years and older $(D=5 \cdot 59$; $\mathrm{df}=1 ; \mathrm{p}=0.018$ )

Sex, marital state, employment status, consumption of alcohol or tobacco, perceived health, and psychological state were of no predictive value.

\section{COMPLIANCE}

At the first follow up interview it was found that 12 patients $(11.5 \%)$ had taken none of the drugs prescribed. Reasons given for not taking the drugs varied, but all had done this on their own initiative. Four patients eventually took the drugs in at least one subsequent month. At one month 33 patients reported taking tricyclic antidepressants in a mean daily dose of $38 \mathrm{mg}$ (range $10-125 \mathrm{mg}$ ). At six months, the mean daily dose for 14 patients was $43 \mathrm{mg}$ (range $10-100 \mathrm{mg}$ ). The mean daily dosages for benzodiazepines at one and six months are given in table III.

\section{Discussion}

An epidemiological perspective on patient care in general practice requires a multicentre design to allow for variability in the behaviour of doctors and patients. ${ }^{45-718}$ Recruiting and maintaining a well defined patient population is a major initiative, which in this study resulted in a small sample size.

We have analysed possible biases in our study. General practitioners contributing patients to the study did not differ from the non-contributors, nor from those who refused to participate, in years since graduation or hours worked. Non-recruitment of eligible patients and under-reporting at follow up interview would tend to reduce rather than exaggerate the estimate of long term use. ${ }^{20}$ Though our study did not include measurements of plasma drug concentrations, our estimate should be regarded as a minimum. Practice based studies using audited prescriptions have produced estimates of long term use that are either consistent with or higher than those in our study. ${ }^{471819}$ Prescription audits avoid the bias in reporting and recall that might affect our results and those of population surveys. Non-compliance, hoarding, and sharing of prescribed drugs with relatives or friends may, however, result in overestimation of the actual use from audits.

Reasons for taking drugs were not sought in this study because pilot work showed this line of questioning to be too threatening. This may be because patients feel guilty about their need for psychotropic drugs. ${ }^{26}$

We have estimated that $15 \%$ of the patients who start treatment with benzodiazepines or antidepressants are still taking the drugs at six months. Ten per cent of short term users of benzodiazepines are still taking the drugs at six months. Twenty three per cent of patients who start treatment with antidepressants continue use for six months.

The three factors that determine continuing use of medication are the drug, the patient, and the doctor. ${ }^{1827}$ Benzodiazepines have a

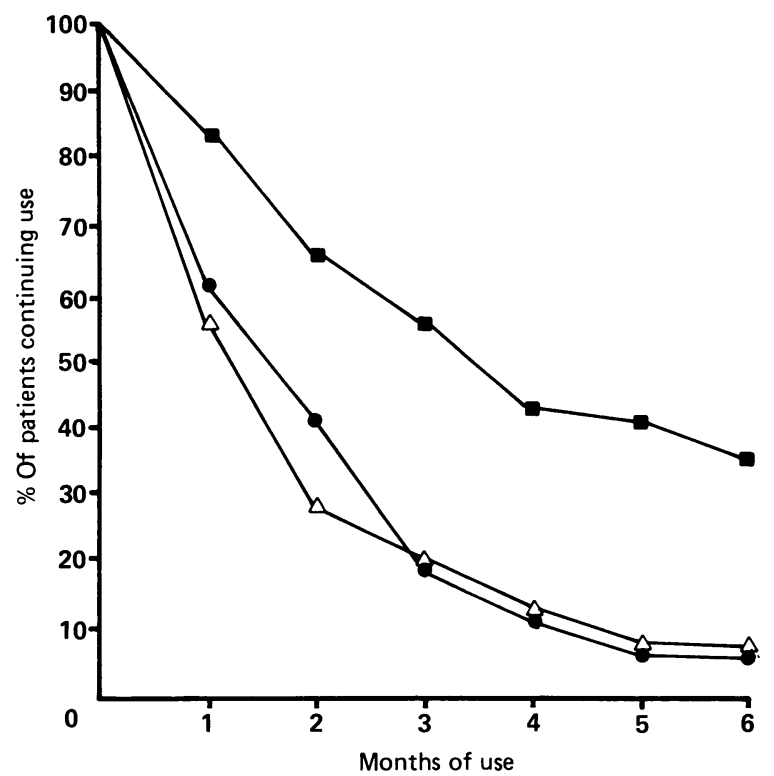

FIG 2-Percentage of new users of psychotropic drugs continuing use over six months, by age group; $\triangle=18-34,0=35-54, \mathbf{\square}=>55$.

TABLE III-Daily doses of benzodiazepines reported by patients one month and six months after starting use

\begin{tabular}{lccccc}
\hline & \multicolumn{2}{c}{ Month 1 } & & \multicolumn{2}{c}{ Month 6 } \\
\cline { 2 - 3 } \cline { 5 - 6 } Benzodiazepine & $\begin{array}{c}\text { Daily } \\
\text { dose }(\mathrm{mg})\end{array}$ & $\begin{array}{c}\text { No of } \\
\text { patients }\end{array}$ & & $\begin{array}{c}\text { Daily } \\
\text { dose }(\mathrm{mg})\end{array}$ & $\begin{array}{c}\text { No of } \\
\text { patients }\end{array}$ \\
\hline Bromazepam & $3-6$ & 3 & & 18 & 1 \\
Chlordiazepoxide & 10,15 & 3 & & $2 \cdot 5$ & 1 \\
Diazepam & 20,40 & 2 & & $1-5$ & 7 \\
Nitrazepam & $2-5$ & 11 & & $22 \cdot 5$ & 1 \\
Oxazepam & $12 \cdot 5-25 \cdot 0$ & 3 & & $2 \cdot 5$ & 1 \\
& $2 \cdot 5,5 \cdot 0$ & 2 & & $7 \cdot 5$ & 1 \\
Temazepam & $7 \cdot 5$ & 1 & & 30 & 3 \\
& 15,30 & 10 & & 10 & 3
\end{tabular}


higher dependency potential than antidepressants. The incidence of continuing use should therefore have been higher among benzodiazepine users, given that patient characteristics did not differ significantly between users of benzodiazepines and users of antidepressants..$^{20}$ Our study, however, confirms an earlier finding that patients who start treatment with antidepressants are more likely to continue use than those given benzodiazepines. ${ }^{18}$ Thus drug and patient factors are not the only determinants of continuing use.

Our study suggests ways in which general practitioners may reduce long term use. The first strategy is to start treatment with psychotropic drugs only after considering the alternatives. The general practitioners in our study started treatment fairly infrequently and thus seem to have used this strategy. ${ }^{20}$ Even when doctors are judicious, however, a second strategy is needed. Treatment should be reviewed regularly. The critical period for review seems to be after the second and before the fourth month.

A third strategy is to be aware of the potential for dependence on drugs among the elderly. Older patients, whether taking benzodiazepines or antidepressants, are more likely to take drugs in the long term, especially the less educated. The elderly have consistently been found to receive more prescriptions for psychotropic drugs and to continue use for longer periods. ${ }^{4618} 19$

Contrary to expectations, neither perceived health nor psychological ill health predict long term use. The sex of the patient also did not predict long term use. We have argued elsewhere that differences in sex probably reflect the greater readiness of women to consult their doctors. ${ }^{27} \mathrm{We}$ did not find that perceived problems in social functioning, feelings of nervousness, or physical symptoms correlated with use in the subsequent month.

We found no evidence of a differential pattern of use of specific generic benzodiazepines. Though another study found that withdrawal symptoms occurred more rapidly in patients using short acting benzodiazepines, the number and type of symptoms did not differ from those seen in patients using long acting benzodiazepines. ${ }^{11} \mathrm{~A}$ larger controlled study is required to explore generic differences.

The doses reported for benzodiazepines were generally low, with a few exceptions. Prescription audits have documented low dosages in general practice. ${ }^{5}$ The doses used by patients in our study were lower than those reported for long term users recruited to trials. ${ }^{8-11} 13$ The doses of antidepressants used were also low compared with those prescribed in psychiatric practice. The effectiveness of low dose antidepressants for general practice patients with depression requires evaluation in a properly controlled trial.

We have argued that prescribing doctors have a significant effect on their patients' patterns of use of drugs. If doctors use the simple strategies of initial patient selection and appropriately timed review they can have an impact on the problem of psychotropic drug dependence.
The study was funded by a health services research grant from the Commonwealth Department of Health and a grant from the Family Medical Care, Education, and Research Foundation of the Royal Australian College of General Practitioners. The Sample Survey Centre, University of Sydney, helped with fieldwork and design of the questionnaire. The School of Community Medicine, University of New South Wales, provided computing facilities. We thank the general practitioners who participated in the study.

\section{References}

1 Chancellor, Mant A, Andrews G. The general practitioner's identification and management of emotional disorders. Aust Fam Physician 1977;6:1137-41.

2 Mellinger GD, Balter MB, Uhlenhuth EH. Prevalence and correlates of the long term regular use of anxiolytics. FAMA 1984;251:375-9.

3 Wells KB, Kamberg C, Brook R, Camp P, Rogers W. Health status, sociodemographic factors and the use of prescribed psychotropic drugs. Med Care 1985;23:1295-1306.

4 Jones L, Simpson D, Brown AC, Bainton D, McDonald H. Prescribing psychotropic drugs in general practice: three year study. $B r$ Med f 1984;289:1045-8.

5 Fleming DM, Cross KW. Psychotropic drug prescribing. I R Coll Gen Pract 1984;34:216-20.

6 Hesbacher P, Rickels K, Rial WY, Segal A, Zamostein BB. Psychotropic drug prescription in family practice. Compr Psychiatry 1976;17:607-15.

7 Skegg DCG, Doll R, Perry J. Use of medicines in general practice. Br Med f 1977;i:1561-3.

8 Petursson $\mathrm{H}$, Lader $\mathrm{MH}$. Withdrawal from long term benzodiazepine treatment. Br Med $\mathcal{J}$ 1981;283:643-5.

9 Tyrer P, Owen R, Dawling S. Gradual withdrawal of diazepam after long term therapy. Lancet 1983;i: 1402-6.

10 Ashton H. Benzodiazepine withdrawal: an unfinished story. Br Med $\mathcal{F}$ 1984;288:1135-40.

11 Busto U, Sellers EM, Narnajo CA, et al. Withdrawal reaction after long term therapeutic use of benzodiazepines. N Engl f Med 1986;315:854-9.

12 Lader M. A practical guide to prescribing hypnotic benzodiazepines. Br Med J 1986;293: 1048-9.

13 Rickels K, Case WG, Schweizer E, et al. Low dose dependence in chronic benzodiazepine users: a preliminary report on 119 patients. Psychopharm Bull 1986;22:407-15.

14 Mellinger GD, Balter MB. Uhlenhuth EH. Insomnia and its treatment. Prevalence and correlates. Arch Gen Psychiatry 1985;42:225-32.

15 Richardson JW, Richelson E. Antidepressants: a clinical update for medical practitioners. Mayo Clin Proc 1984;59:330-7.

16 Morgan HG. Do minor affective disorders need medication? Br Med f 1984;289:783.

17 Catalan J, Gath DH. Benzodiazepines in general practice: time for a decision. Br Med $\mathcal{J}$ 1985;290:1374-6.

18 Williams $P$. Factors influencing the duration of treatment with psychotropic drugs in general practice: a survival analysis approach. Psychol Med 1983;13:623-33.

19 Bridges-Webb C, Mant A, Britt H. Long term psychotropic drug prescribing for general practice patients. Fam Pract 1985;2:238-40.

20 Mant A, Lansbury G, Bridges-Webb C. A survey of new users of psychotropic drugs in Australian general practice. Fam Pract 1987;4:50-5.

21 Goldberg DP. The detection of psychiatric illness by questionnaire. London: Oxford University Press, 1972. (Maudsley Monographs No 21.)

22 Eysenck HJ, Eysenck SBG. Manual of the Eysenck personality inventory. London: University Press, 1964.

23 Shepherd M, Cooper B, Brown AC, Kalton G. Psychiatric illness in general practice. London: Oxford University Press, 1966.

24 Lee $\mathrm{E}$, Desu $\mathrm{M}$. A computer program for comparing $\mathrm{K}$ samples with right censored data. Computer Programs in Biomedicine 1972;2:315-21.

25 Armitage P, Berry G. Statistical methods in medical research. London: Blackwell, 1987:117-26.

26 Gabe J, Lipshitz-Phillips S. Evil necessity? The meaning of benzodiazepine use for women patients from one general practice. Sociology of Health and Illness 1982;4:201-9.

27 Mant A, Broom DH, Duncan-Jones P. The path to prescription: sex differences in psychotropic drug prescribing for general practice patients. Soc Psychiatry 1983;18:185-92.

(Accepted 28 October 1987)

\section{ONE HUNDRED YEARS AGO}

The work of providing dinners for school children in large towns is not only useful; it has become so exceedingly popular that we now see a competition in good works which may lead to the mutual benefit of the various schemes contending in friendly rivalry. We have referred to the difficulties of the economic question in avoiding pauperisation; the competition between vegetarian and mixed diets has been put prominently forward in a report of two conferences held in Manchester on cheap dinners for school children. The Vegetarian Society naturally wish to demonstrate the economical and physiological success of their receipts, while others are not prepared to admit the desirability of excluding animal food. Success or failure in such a matter must be demonstrated by extended experiments. The value of a special diet cannot be demonstrated simply by chemical analysis of the food that ought to be digested, but also must be proved by a prolonged series of observations on the weight and measurements of children, repeated as regular intervals. At present we have no sufficient evidence before us, but we look for such in the future as the outcome of present efforts. It has been found that starving children can eat but little food at these free dinners, and it is said that they digest vegetarian dinners better than animal food. Still many children needing a provision for dinner at or near school are not starving; a separate experience is needed as to the diet most suited to these children, what is best to aid their growth and development, and what do they like best? What diet is followed by most growth and activity in school? Starvation disorders the stomach, producing dyspepsia, loss of appetite, furred tongue, feeble digestion; such is not, we hope, the average condition of children for whom average diets are to be provided. We urge then the desirability of careful and scientific observation of groups of children as to their condition, and as to their feeding, valuable information may thus be attained. It seems desirable to place the vegetarian and mixed dinners in direct competition, and see how the children like and thrive on each respectively. Let one word of warning be given as to vegetarian diet; it has been amply shown that infants under 7 months in large towns are apt to become rachitic if deprived of their natural supply of milk, or cow's milk as its substitute; vegetable food at this age is highly prejudicial to their growth and future development.

(British Medical Fournal 1888;i:201) 